\title{
NIH peer review: Time for some changes
}

US universities guarantee academic freedom to scholars who have demonstrated their professional excellence by means of a tenure system that protects them from reigning intellectual and political pressures. But in the biomedical sciences, tenure has lost much of its meaning since the cost of conducting research now far exceeds any funds or laboratory space directly provided by the universities.

Only 20 years ago, the cost of experimental research in molecular biology was a fraction of a professor's salary; now it is the oppositeseveral times the salary of a professor. Under these conditions, external funding sources have become the de facto checkpoints for the progress of academic biomedical science in the United States. The most significant of these continues to be the US National Institutes of Health (NIH) that annually dispenses billions of research dollars, although only about half actually goes to the favored investigators, since universities now routinely claim $40-50 \%$ of the grant monies as overhead.

As it did 20 years ago, the NIH determines the grant applications to fund by a system of peer review study sections. Because these study sections now wield such power in determining the directions of thinking and modes of experimental inquiries that biomedical sciences will follow, and because they are responsible for dispersing such large public funds, it is absolutely essential that they be free of any potential conflicts of interest, either intellectual or economic.

Disentangling the two is not necessarily straightforward, since many leading academic scientists in biomedicine have financial and other interests in biotechnology companies whose fortunes are often tied to prevailing hypotheses in the very field in which the scientist sits on NIH study sections. A good start, however, would be for the NIH to strictly adhere, both in letter and in spirit, to its current guidelines requiring possible conflicts to be declared prior to being appointed to a particular study section. For example, a scientist who either owned stock in or was a consultant to a biotechnology company developing cancer diagnostics or gene therapy would thus be excluded from study sections reviewing grant applications in those areas.

Ensuring that peer review provides the same measure of academic freedom that it did 20 years ago-when the significantly lower costs, and relative youthfulness of the field contributed to more healthy intellectual competition-may be even more important. It is no secret that NIH grant applicants who offer a maximum of data and a minimum of controversy get the highest scores-hardly a system designed to encourage maximally innovative science.

To simultaneously guard against their rejection of proposals because they threaten vested academic interests, and to enliven them intellectually, NIH study sections should be reconstituted to include nonexpert peers. These would be distinguished scientists, although in fields unrelated to the study section, who would participate as unbiased ombudsmen. Having a few keen physicists argue and judge the merits of proposals in cancer alongside molecular geneticists and tumor immunologists might go a long way to guaranteeing a peer review system that truly supports the sources of scientific innovation that have hitherto made US academic biology so successful.

\section{Taking stock of scientific fraud}

The potential for conflict of interest by academic researchers now extends into a realm of outright fraud that is very much the biotechnology industry's business-and should make biotechnology executives and industry officials active partners in setting standards to help curb such behavior. Recently, for example, the US Federal Securities and Exchange Commission (SEC) charged Milton Mutchnick, the head of gastroenterology at Wayne State University Medical School, with insider trading after the hepatitis B drug Thymosin, on which he was conducting clinical trials for Alpha 1 Pharmaceuticals, turned out to be a dud. Mutchnick and his assistant reportedly moved to tell friends to dump their Alpha stock, which promptly dropped $68 \%$ to $\$ 2$. According to a report in The New York Times, those involved, who were apparently medical doctors themselves, narrowly escaped $\$ 300,000$ in losses.

In another insider trading incident, Dale Lange, a clinical investigator for Cephalon (West Chester, PA) and a professor of neurology at Columbia University's College of Physicians and Surgeons, allegedly bought shares of Cephalon stock in 1994 anticipating the success of
Myotrophin, a protein drug for Lou Gehrig's disease, prior to the announcement of clinical findings. Lange, along with a number of other people associated with Cephalon, all of whom profited handsomely from their insider knowledge, recently settled with the SEC for heavy penalties. Like Mutchnik, they neither admitted nor denied the charges against them. The US government is allowed by law to levy penaity fees of up to three times such ill-gotten earnings or avoided losses.

Reportedly, there are more cases of insider researcher trading in the SEC pipeline. And though many universities and university hospitals have strict guidelines-requiring, for example, that researchers place their stock in companies for which they conduct research into escrow accounts for a period of time after commercialization - these institutions have no way of knowing whether faculty employees are playing by the rules.

Not to put too fine a point on it, those who don't are stealing from the companies that provide them access to inside information in the first place. That makes academic researcher fraud the business of the private sector. 